\title{
Analisa Kerentanan Pada Vulnerable Docker Menggunakan Scanner Openvas Dan Docker Scan Dengan Acuan Standar NIST 800-115
}

\author{
Tika Astriani ${ }^{1}$, Avon Budiyono ${ }^{2}$, Adityas Widjajarto ${ }^{3}$ \\ 1,2,3 Jurusan Sistem Informasi, Fakultas Rekayasa Industri Universitas Telkom, Bandung \\ e-mail:*1tikaastriani@student.telkomuniversity.co.id, ${ }^{2}$ avonbudi@telkomuniversity.co.id, \\ 3adtwjrt@telkomuniversity.co.id
}

\begin{abstract}
Abstrak
Upaya dalam mengukur sebuah kerentanan pada aplikasi dapat dilakukan dengan cara pemindaian, upaya ini berguna untuk menemukan suatu risiko kerentanan sehingga bisa mendapatkan strategi yang tepat untuk mengecilkan atau menghilangan risiko tersebut. Dalam tugas akhir ini, dilakukan analisisa kerentanan pada docker menggunakan vulnerability scanner open source dengan acuan standar NIST 800-155. Penelitian ini menggunakan OpenVAS dan Docker Scan sebagai Vulnerability Scanner yang memiliki database kerentanan yang cukup lengkap serta hasil scanning yang mudah untuk dipahami. Dalam analisa ini,dapat di deteksi dan di analisa macam-macam serangan yang bisa di lakukan oleh attacter dalam melakukan penyerangan. Didapatkan dari hasil profil Analisa risiko serta menunjukkan bahwa WordPress User IDs and User Names Disclosure memiliki resiko tersbesar atas serangan cyber.
\end{abstract}

Kata kunci-Docker,NIST,OpenVAS,Vulnerability

\begin{abstract}
Efforts to measure vulnerabilities in applications can be done by scanning. This effort is useful for finding a risk vulnerability to be appropriate to minimize or eliminate the risk. In this final project, a vulnerability analysis is carried out on Docker using an open-source vulnerability scanner with the NIST 800-155 standard. This study uses OpenVAS and Docker Scan as Vulnerability Scanners that have a fairly complete database of vulnerabilities and scan results that are easily accessible. This analysis can be detected and analyzed the various types of attacks that attackers can carry out in carrying out attacks. Obtained from the risk analysis profile results and shows that WordPress User ID and User Name Disclosure have the greatest risk of cyberattacks.
\end{abstract}

Keywords-Docker,NIST,OpenVAS, Vulnerability

\section{PENDAHULUAN}

$\mathrm{T}$ teknologi merupakan hal yang yang sangat penting dalam kehidupan, terutama untuk kelangsungan dan kenyamanan hidup manusia [1]. Teknologi juga digunakan untuk mempermuadah suatu pekerjaan guna memenuhi kebutuhan sehari-hari , salah satunya yaitu Internet. Di masa pandemi seperti sekarang ini, jaringan internet banyak dimanfaatkan sebagai alat komunikasi yang dapat mempermudah seorang individu maupun organisasi untuk pertukaran informasi jarak jauh yang saling menghubungan antara satu pengguna dengan pengguna lain. 
Dengan mengikuti berkembangnya zaman, tentunya teknologi juga semakin berkembang [2]. Hal ini secara tidak langsung juga menuntut sebuah organisasi dalam memajukan perkembangan perusahaanya, tentunya hampir semua perusahaan baik skala besar maupun kecil menggunakan teknologi informasi untuk meningkatkan layanan bisnis yang di kelolanya dalam meningkatkan perfoma perusahaan.Peningkatan perfoma yang baik bagi perusahaan dibutuhkan suatu teknologi seperti server maupun computer dengan spesifikasi yang bagus, akan tetapi hal tersebut yang menjadi masalah bagi perusahaan terutama untuk perusahaan yang masih beskala kecil dikarenakan memerlukan biaya yang besar. Untuk mengatasi masalah itu dapat digunakan teknologi virtualisasi. Teknologi virtualisasi adalah teknologi mampu menciptakan suatu perangkat virtual seperti sistem operasi, media penyimpanan data dan hardware pada sebuah sistem computer yang sedang berjalan, selain itu teknologi ini dapat mampu menekan biaya untuk membeli infrastruktur yang diperlukan dan peningkatan efektivitas infrastruktur hardware [3].

Salah satu jenis teknologi virtualisasi yaitu virtualisasi server. Virtualisasi server merupakan sebuah server yang di bangun pada computer atau laptop dengan menggunakan media machineware [4]. Dalam membangun virtual machine juga membutuhkan resource yang banyak seperti storage, memory, maupun bandwidth [4].Tak dipungkiri sangat diperlukannya efisiensi penggunaan resource hardware jika ingin menjalakan aplikasi yang lebih banyak lagi, hal tersebut dapay diatasi dengan metode containerization. Container dirasa lebih hemat dalam menkonsumsi resource serta menyediakan metode isolation yang juga disediakan oleh teknologi virtualisasi berbasis virtual machine.

Teknologi terbaru dari container yang dikembangkan oleh Solommon Hykes di dotCloud adalah Docker [5]. Salah satu platform yang dibangun berdasarkan teknologi container [1]. Docker sebagai virtualisasi kontainer memiliki kedudukan yang lebih unggul dibandingkan dengan teknologi virtualisasi container lainnya [6]. Adanya sebuah container di docker memberikan banyak kemudahan, akan tetapi banyak hal yang harus diperhatikan salah satunya mengenai masalah keamanan/ kerentanan yang ada pada Docker. Pencegahan dalam meningkatkan keamanan sebuah sistem dapat di lakukan dengan melakukan uji kerentanan guna membantu dalam proses identifikasi kelemahan pada sistem sebelum adanya serangan. Untuk mendeteksi adanya kerentanan dan melakukan penangganga terhadap kerentanan yang sudah teridentifikasi dapat dilakukakan menggunakan Vulnerability scanner.

Pada penelitian ini, dilakukan analisis mengenai kerentanan pada Docker dengan menggunakan software opensource sebagai vulnerability scanner dan standar NIST 800-115. Pemilihan standar NIST 800-115 di karenakan metodologi mempunyai tahapan yang membantu dalam melakukan analisa,tahapan ini meliputi tahap planning, discovery, attack, dan Reporting. Selain itu dalam analisa ini,dapat di deteksi dan di analisa macam-macam serangan yang bisa di lakukan oleh attacker dalam melakukan penyerangan. Didapatkan 98,6 dari hasil profil Analisa risiko serta menunjukkan bahwa WordPress User IDs and User Names Disclosure memiliki resiko tersbesar atas serangan cyber.

\section{METODE PENELITIAN}

Metode yang digunakan pada anlisis kerentanan pada Docker adalah standar NIST 800115. Pada standar NIST 800-115 terdapat 4 tahapan[7]. yaitu:

\subsection{Planning}

Planning merupakan tahapan yang bertujuan dalam menentukan alur dan persiapan untuk melakukan eksploitasi [8]. Pada tahapan ini juga mengidentifikasi apa saja software dan

Tika Astriani, ei., al [Analisa Kerentanan pada Vulnerable Docker Menggunakan Scanner Openvas dan Docker Scan Dengan Acuan Standar NIST 800-115] 
hardware yang akan digunakan untuk menetukan proses serta tools yang digunakan dalam penelitian ini.

\subsection{Discovery}

Fase Discovery dapat dilakukan setelah tahap planning telah selesai dilaksanakan. Dalam tahapan ini akan dilakukan pencarian informasi serta kerentanan pada vulnerable docker yang akan diuji. Kedua tahapan ini adalah tahapan Information Gathering dan Vulnerability Analysis

\subsection{Attack}

Attack merupakan salah satu tahapan dari metode NIST SP 800-115 untuk melakukan penetrasi terhadap Vulnerable Docker yang diuji untuk melihat kerentanan yang ada dengan melakukan scenario pengambilan data. Untuk memperjelas metode yang digunakan penulis, dapat dilihat pada Gambar 1 mengenai Analisis metode yang penelitian

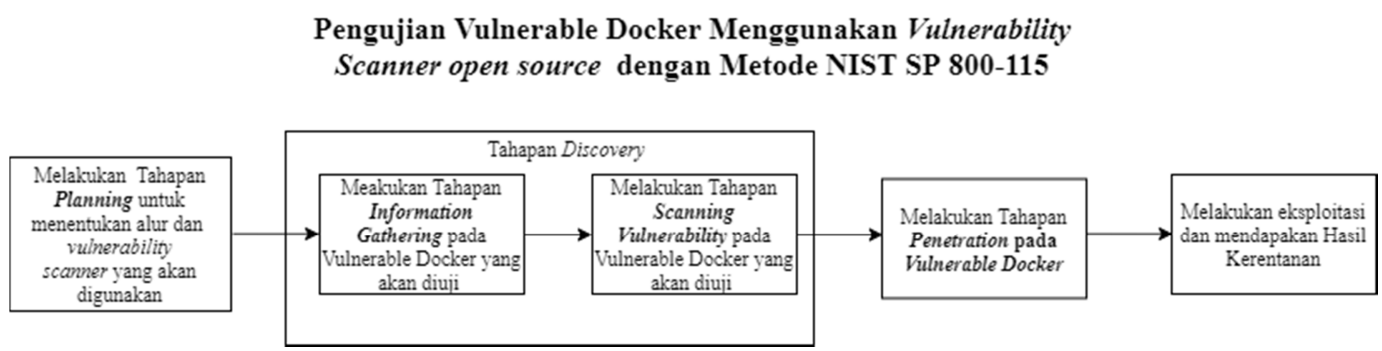

Gambar 1. Pengujian Vulnerable Docker

\section{HASIL DAN PEMBAHASAN}

\subsection{Planning}

Fase Planning merupakan tahapan untuk mencapai tujuan untuk penelitian yang dipaparkan sebelumnya, maka diperlukannya pembuatan environment terlebih dahulu sebelum melakukan proses simulasi yang terdiri dari perangkat keras dan perangkat lunak sebagai langkah awal untuk melakukan analisis walkthrough dari Vulnerable Docker. Environment yang dirancang meliputi VirtualBox sebagai tempat untuk melakukan analisis dengan sistem operasi Kali Linux dan Vulnerable Docker, Sehingga dalam melakukan perancangan sistem membutuhkan beberapa spesifikasi perangkat keras dan spesifikasi perangkat lunak yang berupa alat atau aplikasi pendukung. Pada Tabel 1 merupakan spesifikasi Hardware dan Pada Tabel 2 merupakan Software yang digunakan.

Tabel 1. Spesifikasi Hardware

\begin{tabular}{|c|c|c|}
\hline Komponen & \multicolumn{2}{|c|}{ Informasi } \\
\hline \multirow{3}{*}{$\begin{array}{l}\text { Spesifikasi } \\
\text { Perangkat Keras } \\
\text { (Main OS) }\end{array}$} & Processor & $\begin{array}{l}\text { Intel® } \text { Core }^{\mathrm{TM}} \mathrm{i} 7-2620 \mathrm{M} \\
\mathrm{CP} \\
\mathrm{U} @ 2.70 \mathrm{GHz} \text { (4CPUs), } \\
\sim 2.7 \mathrm{GHz}\end{array}$ \\
\hline & Memory & 8192MB RAM \\
\hline & Hard Disk & $1 \mathrm{~TB}$ \\
\hline
\end{tabular}

Tika Astriani, ei., al [Analisa Kerentanan pada Vulnerable Docker Menggunakan Scanner Openvas dan Docker Scan Dengan Acuan Standar NIST 800-115] 


\begin{tabular}{|l|l|l|}
\hline & System Type & 64-bit \\
\cline { 2 - 3 } & Operating System & $\begin{array}{l}\text { Microsoft Windows 10 } \\
\text { Education }\end{array}$ \\
\hline
\end{tabular}

Tabel 2. Spesifikasi Software

\begin{tabular}{|l|l|l|}
\hline \multicolumn{1}{|c|}{ Type } & \multicolumn{1}{|c|}{ Software } & \multicolumn{1}{c|}{ Versi } \\
\hline Operating System & Kali Linux & 2020.3 \\
\hline Asset IT & Vulnerable Docker & 2017 \\
\hline \multirow{2}{*}{ Attack Tools } & Nmap & 7.91 \\
\cline { 2 - 3 } & WpScan & 3.8 .17 \\
\hline \multirow{2}{*}{$\begin{array}{l}\text { Vulnerability Scanning } \\
\text { Tools }\end{array}$} & OpenVAS & 21.04 .0 \\
\cline { 2 - 3 } Third Party Program & DockerScan & V0.8.0 \\
\hline
\end{tabular}

\subsection{Discovery}

Fase Discovery dapat dilakukan setelah tahap planning telah selesai dilaksanakan. Dalam tahapan ini akan dilakukan pencarian informasi serta kerentanan pada Vulnerable Docker yang akan diuji. Kedua tahapan ini adalah tahapan Information Gathering dan Vulnerability Analysis.

Dalam fase Information Gathering akan dilakukan pencarian informasi dan pengumpulan data terkait yang akan digunakan terhadap target, data tersebut berupa Topologi eksperimen dan IPAddress. Tologi eksperimen digunakan dalam simulasi langkah pada eksperimen untuk mendapatkan suatu kerentanan yang terdapat pada Docker.

Pada Gambar 2 merupakan topologi eksperimennya Platform dan dijelaskan mengenai topologi fisisk yang terdiri dari Internet, Main $O S$, virtual machine (Kali Linux) yang berisikan scanner opensource, virtual machine (Ubuntu) yang berisikan Vulnerable Docker. Internet yang menghubungan seluruh operating system yang sedang berjalan. Ubuntu yang terhubung dengan Vulnerable Docker agar dapat melakukan identifikasi Internet Protocol (IP) dan dapat melakukan eksploitasi menggunakan tools yang relevan untuk mengetahui kerentanan pada Vulnerable Docker. Kemudian pada Kali Linux juga terhubung dengan open source vulnerability scanner OpenVAS sebagai scanner yang bertujuan untuk mendapatkan data hasil kerentanan.Sementara pada Gambar x dijelaskan IP Address yang digunakan pada penelitian.

Tika Astriani, ei., al [Analisa Kerentanan pada Vulnerable Docker Menggunakan Scanner Openvas dan Docker Scan Dengan Acuan Standar NIST 800-115] 


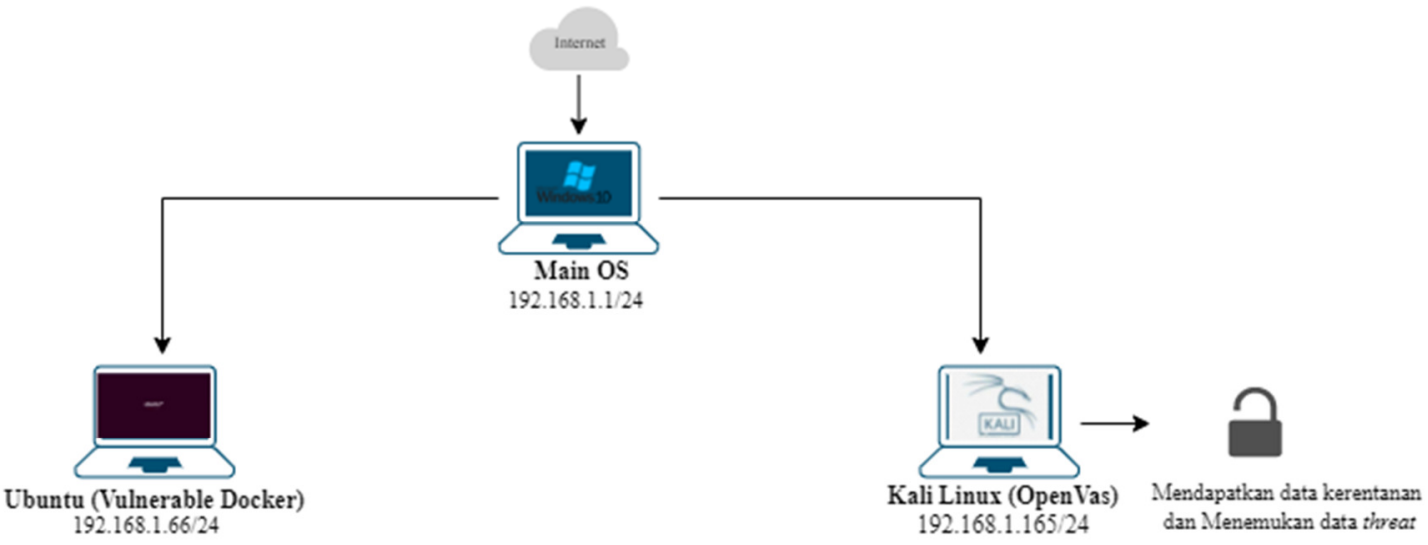

Gambar 2. Platform Eksperimen

Pada Tabel 3 merupakan daftar IP Address yang digunakan pada penelitian ini

Tabel 3. Daftar IP Address

\begin{tabular}{|c|c|c|c|}
\hline Nama & Host & Default Gateway & IP Address \\
\hline Main OS & Windows 10 & \multirow{4}{*}{ 192.168.1.2 } & 192.168.1.1/24 \\
\hline \multirow[b]{2}{*}{ VM 1} & \multirow[t]{2}{*}{ Kali Linux } & & $192.168 .1 .165 / 24$ \\
\hline & & & 192.168.1.66/24 \\
\hline VM 2 & $\begin{array}{l}\text { Ubuntu } \\
\text { (Vulnerable } \\
\text { Docker) }\end{array}$ & & 192.168 .1 .66 \\
\hline
\end{tabular}

\subsection{Attack}

Attack merupakan salah satu tahapan dari metode NIST SP 800-115 untuk melakukan penetrasi terhadap Vulnerable Docker yang diuji untuk melihat kerentanan yang ada dengan melakukan scenario pengambilan data. Skenario Pengujian Vulnerability Scanninng Menggunakan OpenVAS dan Docker Scan merupakan alur dilalukannya analisis vulnerability pada environtment yang sudah dirancang sebelumnya dengan cara menganalisis vulnerability pada Vulnerable Docker. Berdasarkan Gambar 3 menjelaskan skenario pengujian dalam penelitian ini 


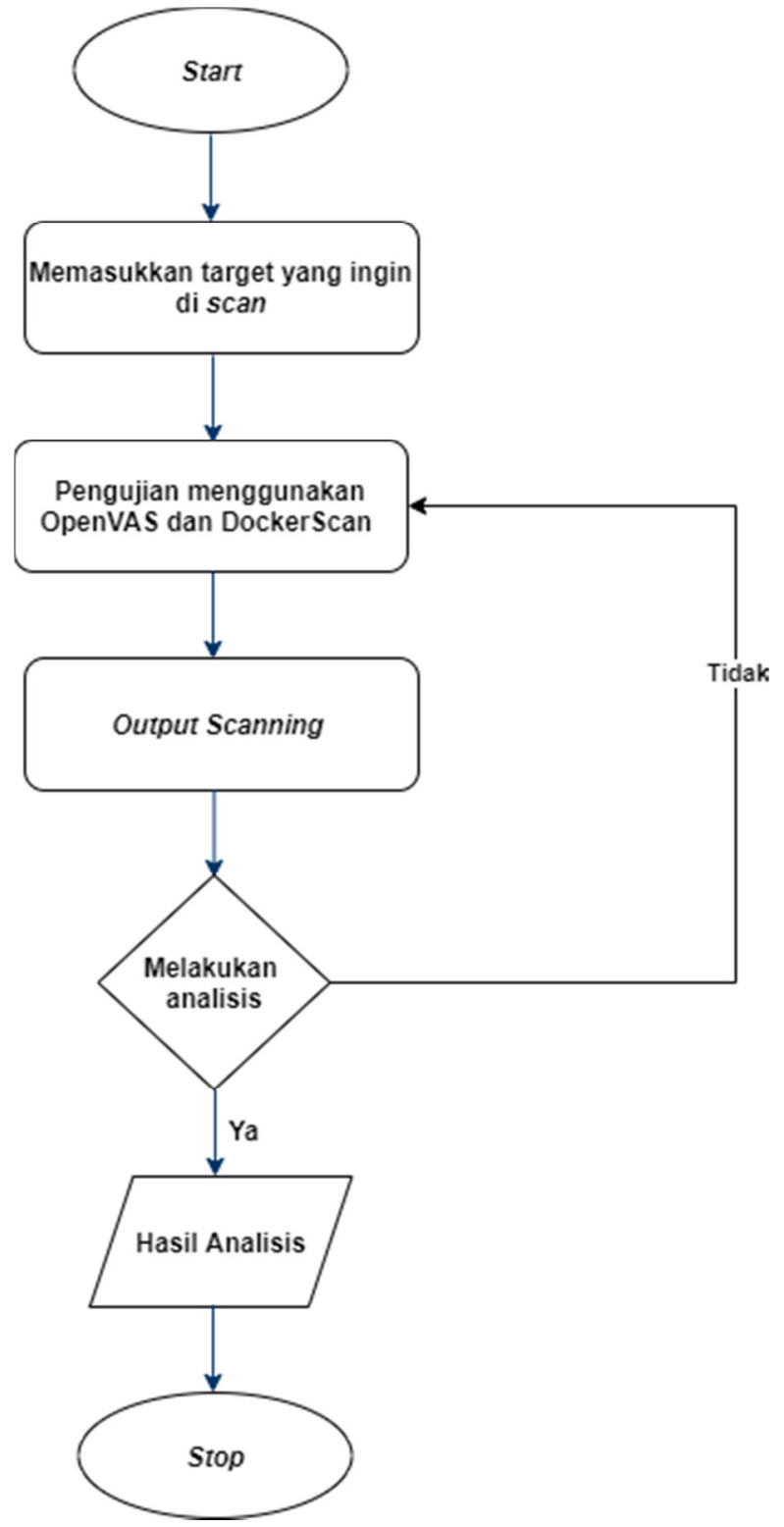

Gambar 3. Skenario Pengujian

Pada Gambar 3 diketahui bahwa tahapan pertama dengan memasukkan target yang akan di scan selanjutnya lakukan scanning menggunakan OpenVAS dan Docker Scan. Selanjutnya akan mendapatkan hasil scanning yang berupa beberapa vulnerabilities yang dapat di analisis pada tahap selanjutnya. Pada hasil analisis dilakukan secara manual menganalisa kerentanan yang didapatkan dan di kategorikan berdasaekan threat level yang dihasilkan.

Tika Astriani, ei., al [Analisa Kerentanan pada Vulnerable Docker Menggunakan Scanner Openvas dan Docker Scan Dengan Acuan Standar NIST 800-115] 


\subsubsection{Hasil Scanning}

Berdasarkan pengujian yang dilakukan pada Docker menggunakan tool OpenVAS didapatkan hasil seperti pada Tabel 4.

Tabel 4. Hasil Pengujian Menggunakan OpenVAS

\begin{tabular}{|c|c|c|}
\hline Host & Threat Level & Total \\
\hline \multirow{4}{*}{$\begin{array}{l}\text { Vulnerable } \\
\text { Docker }\end{array}$} & High & 0 \\
\hline & Medium & 5 \\
\hline & Low & 2 \\
\hline & Info & 24 \\
\hline
\end{tabular}

Pada Tabel 4 diketahui bahwa hasil pengujian dengan menggunakan OpenVAS pada Docker ditemukan kerentanan dengan risiko level High sebanyak nol, level Medium sebanyak lima, level Low sebanyak dua serta Info sebanyak dua puluh empat.

Hasil scanning menggunakan Docker Scan ditemukan kerenyanan dengan risiko level High sebanyak nol, level Medium sebanyak lima, level Low sebanyak dua seperti pada Tabel 5

Tabel 5. Hasil Pengujian Menggunakan Docker Scan

\begin{tabular}{|c|c|c|}
\hline Host & Threat Level & Total \\
\hline \multirow{3}{*}{$\begin{array}{l}\text { Vulnerable } \\
\text { Docker }\end{array}$} & High & 0 \\
\hline & Medium & 6 \\
\hline & Low & 2 \\
\hline
\end{tabular}

\subsubsection{Analisa Frekuensi Serangan}

Setelah mendapatkan vulnerability dari Vulnerable Docker. Pada Tabel 6 merupakan daftar frekuensi tools serangan yang digunakan pada walkthrough.

Tabel 6. Analisa Frekuensi Tools Serangan

\begin{tabular}{|l|c|c|c|c|c|c|c|}
\hline \multirow{2}{*}{ Threat ID } & \multirow{2}{*}{ Attack Threat } & \multicolumn{5}{|c|}{ Walktrough } & \multirow{2}{*}{ Score } \\
\cline { 3 - 8 } & & 1 & 2 & 3 & 4 & 5 & \\
\hline Thx1 & Port Scanning & $\mathrm{V}$ & $\mathrm{V}$ & $\mathrm{V}$ & $\mathrm{V}$ & $\mathrm{V}$ & 5 \\
\hline Thx2 & Brute Force & $\mathrm{V}$ & $\mathrm{V}$ & $\mathrm{V}$ & $\mathrm{V}$ & $\mathrm{V}$ & 5 \\
\hline Thx3 & SSH Enumeration & $\mathrm{V}$ & $\mathrm{V}$ & $\mathrm{V}$ & $\mathrm{V}$ & $\mathrm{V}$ & 5 \\
\hline Thx4 & WpScan & $\mathrm{V}$ & $\mathrm{V}$ & $\mathrm{V}$ & $\mathrm{V}$ & $\mathrm{V}$ & 5 \\
\hline Thx5 & Sql Injection & & & $\mathrm{V}$ & & & 1 \\
\hline
\end{tabular}

Tika Astriani, ei., al [Analisa Kerentanan pada Vulnerable Docker Menggunakan Scanner Openvas dan Docker Scan Dengan Acuan Standar NIST 800-115] 
Tabel 6 menjelaskan mengenai frekuensi dari masing-masing tools pada setiap walktrough untuk melakukan eksploitasi pada Vulnerable Docker yang dihitung berdasarkan banyaknya penggunaan tools.

Risiko adalah konsekuensi atau potensi kehilangan serta akibat yang dapat terjadi pada suatu proses atau dalam konteks penelitian kali ini yaitu kerentanan dari proses eksploitasi [9]. Tujuan dari penilaian risiko adalah untuk mengindentifikasi dan menilai potensi ancaman, kerentanan dan risiko dimana akan berdampak terhadap layanan dan operasi utamanya. Sedangkan menurut Stephen Watts pada BMC formula perhitungan resiko[10]. Dapat di definisikan sebagai:

$$
\text { Risk }=\text { Vulnerability } x \text { Threat }
$$

Dapat dilihat pada tabel 7, risiko tertinggi didapatkan oleh Vulnerability jenis WordPress User IDs and User Names Disclosure dengan total 116.

Tabel 7. Analisa Risiko

\begin{tabular}{|c|c|c|c|c|c|c|}
\hline No & Vulnerability & CVSS & Threat ID & Frequency & Risk & Total \\
\hline \multirow{4}{*}{1.} & \multirow{4}{*}{$\begin{array}{l}\text { WordPress User } \\
\text { IDs and User } \\
\text { Names } \\
\text { Disclosure }\end{array}$} & \multirow{4}{*}{5.8} & Thx 1 & 5 & 29 & \multirow{4}{*}{116} \\
\hline & & & Thx 2 & 5 & 29 & \\
\hline & & & Thx 3 & 5 & 29 & \\
\hline & & & Thx 4 & 5 & 29 & \\
\hline \multirow{4}{*}{2.} & \multirow{4}{*}{$\begin{array}{l}\text { WordPress } \\
\text { Multiple } \\
\text { Vulnerabilities - } \\
\text { July09 }\end{array}$} & \multirow{4}{*}{5.0} & Thx 1 & 5 & 25 & \multirow{4}{*}{100} \\
\hline & & & Thx 2 & 5 & 25 & \\
\hline & & & Thx 3 & 5 & 25 & \\
\hline & & & Thx 4 & 5 & 25 & \\
\hline \multirow{3}{*}{3.} & \multirow{3}{*}{$\begin{array}{l}\text { WordPress / } \\
\text { WordPress MU } \\
\text { Multiple } \\
\text { Vulnerabilities- } \\
\text { July09 }\end{array}$} & \multirow{3}{*}{5.0} & Thx 1 & 5 & 25 & \multirow{3}{*}{75} \\
\hline & & & Thx 3 & 5 & 25 & \\
\hline & & & Thx 4 & 5 & 25 & \\
\hline \multirow{3}{*}{4.} & \multirow{3}{*}{$\begin{array}{l}\text { Cleartext } \\
\text { Transmission of } \\
\text { Sensitive } \\
\text { Information via } \\
\text { HTTP }\end{array}$} & \multirow{3}{*}{4.8} & Thx 1 & 5 & 24 & \multirow{3}{*}{72} \\
\hline & & & Thx 2 & 5 & 24 & \\
\hline & & & Thx3 & 5 & 24 & \\
\hline
\end{tabular}

Tika Astriani, ei., al [Analisa Kerentanan pada Vulnerable Docker Menggunakan Scanner Openvas dan Docker Scan Dengan Acuan Standar NIST 800-115] 


\begin{tabular}{|c|c|c|c|c|c|c|}
\hline \multirow{3}{*}{5.} & \multirow{3}{*}{$\begin{array}{l}\text { SSH Weak } \\
\text { Encryption } \\
\text { Algorithms } \\
\text { Supported }\end{array}$} & \multirow{3}{*}{4.3} & Thx 1 & 5 & 21.5 & \multirow{3}{*}{47,3} \\
\hline & & & Thx3 & 5 & 21.5 & \\
\hline & & & Thx 5 & 1 & 4.3 & \\
\hline \multirow{3}{*}{6.} & \multirow{3}{*}{$\begin{array}{l}\text { SSH Weak MAC } \\
\text { Algorithms } \\
\text { Supported }\end{array}$} & \multirow{3}{*}{2.6} & Thx 1 & 5 & 13 & \multirow{3}{*}{28,6} \\
\hline & & & Thx3 & 5 & 13 & \\
\hline & & & Thx 5 & 1 & 2.6 & \\
\hline \multirow{2}{*}{7.} & \multirow{2}{*}{ TCP Timestamp } & \multirow{2}{*}{2.6} & Thx 1 & 5 & 13 & \multirow{2}{*}{26} \\
\hline & & & Thx 3 & 5 & 13 & \\
\hline
\end{tabular}

\section{KESIMPULAN}

Berdasarkan analisis kerentanan menggunakan OpenVas pada Vulnerable docker berdasarkan metode NIST 800-115 dapat disimpulkan sebagai berikut:

Bedasarkan software open source OpenVAS bahwa di dapatkan hasil 7 Vulnerabilty, Sedangkan hasil yang diperoleh menggunakan Docker Scan di dapatkan 8 Vulnerability yang di kategorikan dalam threat level High, Medium dan Low. Dengan di lakukannya klasifikasi hasil dari Vulnerabilty scanning berdasarkan frekuensi penggunaan tiap walktrough, hasil vulnerability dengan nilai perhitungan resiko tertinggi sebesar terdapat pada WordPress User IDs and User.

\section{SARAN}

Setelah dilakukannya analisis, terdapat saran yang dihasilkan dalam penelitan ii sebagai berikut:

1. Perlu dilakukannya penelitian lebih spesifik dengan menggunakan software lainnya.

2. Melakukan lebih banyak pengujian menggunakan walkthrough dengan skala lebih luas.

3. Disarankan menggunakan open source vulnerability selain OpenVAS untuk melakukan vulnerability assessment.

4. Melakukan analisa dengan menggunakan selain standar NIST 800-115, seperti PTES ataupun OWASP. 


\section{DAFTAR PUSTAKA}

[1] P. Web, 2017, "Kecanggihan Tak Terbatas (Juara 3 Lomba Artikel TIK Pustekkom 2016),” pusdatin.kemdikbud, https://pusdatin.kemdikbud.go.id/kecanggihan-takterbatas-juara-3-lomba-artikel-pustekkom-2016/ (accessed Jul. 25, 2021).

[2] M. Ngafifi, 2014, "Kemajuan Teknologi dan Pola Hidup Manusia Dalam Perspektif Sosial Budaya,” J. Pembang. Pendidik. Fondasi dan Apl., Vol. 2, No. 1, pp. 33-47, doi: 10.21831/jppfa.v2i1.2616.

[3] A. Aziz and A. Tarkono, 2016, "Teknologi Virtualisasi Openvz dan Kernel-Based Virtual Machine sebagai Layanan IaaS pada Jaringan Enterprise," Multinetics, Vol. 2, No. 1, p. 24, doi: 10.32722/multinetics.Vol. 2.No.1.2016.pp.24-30.

[4] T. Prasandy and W. Adhiwibowo, 2015, "Virtualisasi Server Sederhana Menggunakan Proxmox,” J. Transform., Vol. 12, No. 2, p. 37, doi: 10.26623/transformatika.v12i2.80.

[5] Y. K, 2018. "Containerization, Teknologi Masa Depan Pengganti Virtualization," Niagahoser, https://www.niagahoster.co.id/blog/docker-tutorial/ (accessed Jul. 25, 2021).

[6] F. Adiputra, 2015. "Container dan Docker: Teknik Vertualisasi Dalam Pengelolaan Banyak Aplikasi Web,” J. SimanteC, Vol. 4, No. 3,

[7] NIST 800-115, 2008, "Technical Guide to Information Security Testing and Assessment Recommendations of The National Institute of Standards and Technology," Nist Spec. Publ., vol. 800, pp. 1-80, [Online]. Available: http://books.google.com/books?

[8] A. Methodology, R. Techniques, T. Identification, and N. Port, "NIST SP800-115," pp. $1-9$.

[9] E. Seth Misenar, J , Conrad, 2010. CISSP Study Guide.

[10] S. Watts, 2020. "IT Security Vulnerability vs Threat vs Risk: What are the Differences?,” https://www.bmc.com/blogs/security-vulnerability-vs-threat-vs-riskwhats-difference/ (accessed Jul. 20, 2021). 